\title{
Étymologie et monoprophétisme: Réflexions sur les hanifs du Coran entre mythe et histoire
}

\author{
Claude Gilliot
}

Il ne sera pas traité ici de l'ensemble du dossier concernant ceux que Julius Wellhausen (1844-1918) appela autrefois: «les chercheurs» [de Dieu] (Sucher) ${ }^{1}$ ou les «pieux dissidents» ([die] frommen Dissenters $){ }^{2}$ Cela fut exprimé avec beaucoup d'à propos, tout au moins à l' intérieur d' un certain contexte qui n' est pas directement celui du texte coranique, tel qu'il nous a été transmis à travers les avatars que l'on sait. ${ }^{3}$ La notion de dissidence est idoine, car l'une des idées générales renfermée dans haniff en arabe est: «qui a les pieds en lanières, ne se tient pas sur ses jambes, et qui pour ainsi dire boite» (loripes fuit... ac tanquam claudicavit), d'où vient l'idée d'être instable ou inconstant dans ses idées. ${ }^{4}$ Wellhausen pensait que c' est de certains de ces person-

1 Julius Wellhausen, Skizzen und Vorarbeiten, Vol. 3: Reste arabischen Heidentums (Berlin: Georg Reimer, 1887), 203; Julius Wellhausen, Reste arabischen Heidentums (Berlin: Walter de Gruyter, 1927), 234.

2 Wellhausen, Skizzen, 3 :209; Wellhausen, Reste, 238; Gustav Edmund von Grunebaum, Classical Islam: A History, 600 A.D. to 1258A.D., trans. Katherine Watson (London: Allen and Unwin, 1970), 25, écrit de même: «The Arabic meaning - approximatively: confessionally unaffiliated monotheist -, is best understood if hanpā or hanīf be taken first and foremost to mean: dissenter, and dissenters, individualists, the hunafä remained».

3 Pour ces avatars et ces ambiguïtés, $\nu$. Claude Gilliot, «Collecte ou mémorisation du Coran. Essai d' analyse d' un vocabulaire ambigu, » in Hadîtstudien - Die Überlieferungen des Propheten im Gespräch. Festschrift für Prof. Dr. Tilman Nagel, ed. Rüdiger Lohlker (Hamburg: Verlag Dr. Kovač, 2009), 77-132.

4 Johann David Michaelis, Supplementa ad Lexica Hebraica, 6 vols. (Göttingen: Johann Georg Rosenbusch, 1792), 3: 848-852, no. 79o, spécialement 849; cf. Max Grünbaum, «Miscellen,» Zeitschrift der Deutschen Morgenländischen Gesellschaft 42 (1888): 54-55; François de Blois,

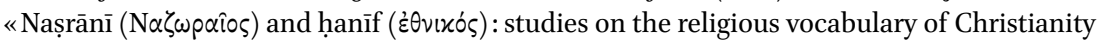
and of Islam,» Bulletin of the School of Oriental and African Studies 65, vol. 1 (2002): 18-19, a rassemblé des sens plus ou moins proches dans plusieurs langues sémitiques, $v . g$. hébr. hānef «être souillé» (sens premier), hanêf : «impie» ou «hypocrite,» encore qu' on diverge sur le sens précis; syriaque: hanpā : «païen». 
nages marqués par les ascètes chrétiens, peut-être chrétiens eux-mêmes, que Muhammad reçut ses premières impulsions (seine ersten Anregungen), alors qu' il était encore à la Mecque. De fait, celui qui s' établit progressivement prophète, et/ou qu' on créa peu à peu prophète, se manifesta d' abord avec l'idée du jugement: «Allah et le jour du jugement dernier sont chez lui inséparable ». ${ }^{5}$ Pour le hanīfisme des ennemis de Muhammad et celui de la Mecque avant l'hégire, on se reportera àl'étude d'Uri Rubin qui a introduit beaucoup de clarté à ce sujet. ${ }^{6}$ Plus récemment, Jan Van Reeth a essayé de retrouver les antécédents des prophéties oraculaires de Muhammad chez Montan et Mani. Grâce à cette étude, nous avons une idée plus nette des origines et de la nature du «ḥanīfisme mitigé» (al-ḥanīfiyya al-samha) qui aurait été celui de Muḥammad. ${ }^{7}$

Dans la présente contribution, nous nous concentrerons sur trois points. Tout d'abord l'ambivalence, voire l' ambiguïté cultivée, du terme hanäf dans le Coran. Notre deuxième objectif sera de montrer que le Coran utilise souvent ce vocable dans un contexte polémique pour asseoir et enraciner le quasi postulat du «monoprophétisme» de Muhammad. Enfin il apparaîtra que ce mot énantiosémique ressortit à un phénomène bien connu des linguistes: la contamination ou analogie linguistique, ce qu' avait bien vu l' excellent sémitisant qu'était le Père Paul Joüon, s. j. (1871-1940), sans qu'il utilisât ce jargon.

5 Wellhausen, Skizzen, 203. Cette importante remarque fut développée dans le remarquable travail de Paul Casanova, Mohammed et la fin du monde. Étude critique sur l'islam primitif (Paris: Paul Geuthner, 1911-1924), 18, 207-213: nabī/rasūl ākhir al-zamān: «prophète de la fin des temps». Pour Casanova, 228, cette expression est identique à khātam (khātim?) alnabiyyīn, qui est bien une notion apocalyptique; cf. Daniel 4:24; Aggée 2: 23 (khotam en hébreu). Alfred Guillaume, The Life of Muhammad: A Translation of Ibn Ishaq's Sirat Rasul Allah (Karachi: Oxford University Press, 1955), 7: «in time to come» (Arabic: fì äkhir alzamān).

6 Uri Rubin, «Hanīfiyya and Ka'ba: an inquiry into the Arabian pre-Islamic background of dīn Ibrāhīm,» Jerusalem Studies in Arabic and Islam 13 (1990): 85-103.

7 Jan M.F. van Reeth, «Les prophéties oraculaires dans le Coran et leurs antécédents: Montan et Mani, » in Controverses sur les écritures canoniques de l'islam, eds. Daniel De Smet and Mohammad Ali Amir-Moezzi (Paris: Cerf, 2014), 109-113; Moshe Gil, «The creed of Abū 'Āmir, » Israel Oriental Studies 12 (1992): 43. 
Le vocable hanīf apparaît dans le Coran ${ }^{8}$ dix fois au singulier et deux fois au pluriel (hunaf $\tilde{a})$. Dans huit de ces emplois au singulier, il est fait référence à la foi supposée d'Abraham (Ibrähīm; Q 2: 135, 3: 67, 95, 4: 125, 6: 79, 161, 16: 120, 123); les deux occurrences dans lesquelles Abraham ne figure pas sont: Q 10: 105 et 30: 30. Cinq des huit versets mentionnant le Patriarche comportent l' expression millat Ibrähìm (Q 2:135, 3: 95, 4:125, 6, 161, 16:123). Quant aux deux occurrences au pluriel, ce sont Q 22: 31 et Q 98: 5. Dans neuf cas, une phrase (explicative) est ajoutée qui signifie que pour être hanīf, il ne faut pas être assocationniste (mushrik) (Q 2:135, 3:67, 3: 95, 6: 79, 6: 161, 10: 105, 16: 120, 16:123, 22: 31). ${ }^{9}$ On a remarqué que ce dernier terme à l'intérieur d'une déclaration polémique ne signifie pas obligatorement «polythéistes» ou «idolâtres» au sens réel du terme, «l'islam devant être compris comme le résultat d'une polémique ${ }^{10}$ intra-monothéiste, à l'intérieur d'un processus similaire à celui de l'émergence des autres principales divisions du monothéisme».11

De ce point de vue, nous prenons nos distances sur certains points importants par rapport à un l' article et un ouvrage de Fred Donner. ${ }^{12}$ Nous ne partageons pas ses idées sur le caractère soi-disant «œcuménique ${ }^{13}$ du message de Muhammad et des «croyants» (mu'minūn) qui y adhéraient. En effet, le prophétisme de Muhammad se donne à voir, à notre avis, comme un «monoprophétisme $»^{14}$, tous les «prophètes» antérieurs, «historiques» ou «mythi-

$8 V$. Andrew Rippin, «R R ب̣m and the Hanīfs,» in Islamic Studies presented to Charles J. Adams, eds. Wael B. Hallaq and Donald P. Little (Leiden: Brill, 1991), 158, pour la traduction anglaise de ces versets selon l'ordre du Coran actuel; Arthur Jeffery, The Foreign Vocabulary of the Qur'ān (Baroda: Oriental Institute, 1938), 112-115.

$9 \quad$ Jeffery, Foreign Vocabulary, 112; Mun'im Sirry, «The Early Development of the Quranic Hanīf,» Journal of Semitic Studies 59, no. 2 (2011): 349-355, a relevé ces caractéristiques du hanīf coranique et quelques autres encore.

10 Sur l'usage polémique de hanīf, $v$. Milka Levy-Rubin, «Praise or defamation? On the Polemical Usage of the Term Hanīf among Christians and Muslims in the Middle Ages, Jerusalem Studies in Arabic and Islam 28 (2003): 202-224.

11 Gerald R. Hawting, The Idea of Idolatry and the Emergence of Islam:From Polemic to History (Cambridge: Cambridge University Press, 1999), 7.

12 Fred Donner, «From Believers to Muslims. Confessional Self-Identity in the Early Islamic Community, » Al-Abhath 50-51 (2002-2003): 9-53; Idem, Muhammad and the Believers. At the Origins of Islam (Cambridge: The Belknap Press, 2010).

13 Donner, Muhammad and the Believers, 68-74.

14 Alfred-Louis de Prémare, «L'islam comme monoprophétisme,» in Vivre avec l'islam. Réflexions chrétiennes sur la religion de Mahomet, éd. Annie Laurent (Versailles: Éditions Saint-Paul, 1996), 150-162. 
ques», ou encore dont l'existence historique n'est point attestée, étant vus selon l'image unitaire que Muhammad et/ou les premières communautés avaient de la mission prophétique qui, dans cette représentation, culminait dans la sienne. Le Coran aboutit à une sorte de «psittacisme prophétique» (l' expression est de nous), dans lequel tous les prophètes, tels des «perroquets de Dieu », délivrent matériellement le même message, «confirmé» par celui de Muhammad ${ }^{15}$. De la sorte le soi-disant «œcuménisme» n' est que de façade: les annonceurs antérieurs ne sont là que pour préparer l'Annonceur par excellence, Muhammad. Bien plus, ils sont vus tels qu'il se voyait ou s' est vu peu à peu, au gré de son évolution psychologique et sociale, ou bien encore tel que ceux qui l' ont aidé ou conseillé formaient son image.

De plus, Donner accorde bien peu de place à la stratégie de la violence à laquelle Muhammad eut largement recours pour faire triompher son entreprise $^{16}$, notamment l'exécution et la décapitation des mâles de la tribu juive des banū Qurayẓa et la réduction à l'esclavage de leurs femmes et de leurs enfants. ${ }^{17}$

Il est un de ces versets polémiques contenant le terme hanif relevés plus haut qui pose problème, c'est Q 16:120, dans lequel il est dit qu'Abraham était une umma,$^{18}$ ce qui est entendu par la plupart des exégètes: «modèle», «parangon de vertu», etc. Aloys Sprenger, à notre avis, avait compris qu' il fallait rester plus près du texte et traduisit par «ein gottergebenes Volk» (ummatan qānitan (i-llāh), mais il n' en donna pas la justification. Or celle-ci se trouve en Genèse 18: 18, où il est dit qu'Abraham «deviendra un grand peuple (yihyeh laḡoy gādōl) et par lui se béniront toutes les nations de la terre», ainsi que l'a bien relevé Gabriel Reynolds. ${ }^{19}$ La même idée se trouve aussi en Gen 12: 2 et 22, 17-18. De même que Muhammad est le prophète «gentil» (ummī), Abra-

15 Claude Gilliot, «Rétrospectives et perspectives. De quelques sources possibles du Coran mecquois, » in Perspectives on Islamic Culture. Essays in Honour of Emilio G. Platti, ed. Bert Broeckaert, et al. (Louvain-Paris: Peeters, 2013), 41, Idem, «Narratives, »EQ, 3, 516-528.

16 Claude Gilliot, «Poète ou prophète? Les traditions concernant la poésie et les poètes attribuées au prophète de l'islam et aux premières générations musulmanes, » in Paroles, signes, mythes. Mélanges offerts à Jamal EddineBencheikh, ed. Floréal Sanagustin (Damas: IFEAD, 2001), 331-396; pour la stratégie de la violence, 380-388 (IX. Prophétie contre poésie. De la construction d'un prophète).

17 Donner, Muhammad and the Believers, 47.

18 Jacqueline Chabbi, Les trois piliers de l'islam: lecture anthropologique du Coran (Paris: Seuil, 2016), 184 et n. 4, relie umma à imām, et y voit les sens suivants: voie, guide et groupe bien guidé. C' est possible, mais on reste alors enfermé dans l' ilôt coranique "préservé» de toute intertextualité. Ce n' est pas ainsi qu'une religion ou une culture vient au jour.

19 Gabriel Said Reynolds, The Qur'än and its Biblical Subtext (London: Routledge, 2010), 8485 . 
ham est aussi le prophète des «gentils», des «païens ${ }^{20}$, des non-juifs. Ainsi, ummī et hanäf se retrouvent dans la «gentilité». Nous avons une fois de plus une manifestation du monoprophétisme de Muhammad ou du Coran.

Pour ce qui est de l'ordre chronologique des passages coraniques qui nous occupent ici, on sait que Christiaan Snouck Hurgronje (1857-1936) range ceux dans lesquels Abraham est qualifié de hanîf et de muslim dans la période médinoise. ${ }^{21}$ Il va même plus loin, prétendant que Muhammad n' avait pas d'intérêt spécial pour les patriarches hébreux dans la période ancienne de sa carrière prophétique. ${ }^{22}$ Cela dit, il reconnaît sa dette à l'égard d'Aloys Sprenger (1813-1893), ${ }^{23}$ alors même que ce dernier considérait Q 6: 161 mecquois. ${ }^{24}$ Il faut dire que l'opus magnum du grand savant et médecin autrichien renferme, entre autres, la première étude exhaustive sur Abraham, et notamment sur les hanīf s. ${ }^{25}$ Comme on le sait cette sourate fait problème; mais Régis Blachère lui a donné le numéro 91 dans sa chronologie. ${ }^{26}$

Pour Youakim Moubarac (1924-1995), «Abraham est dit Hanîf dès la fin de la troisième période mecquoise tout au moins, et c'est sa caractérisation fondamentale du point de vue religieux», 27 et de renvoyer «tout au moins» à Q 30: 30 (29 dans la numérotation de Coufa) et à Q 10:105. ${ }^{28}$ On peut faire de

$20 \quad$ Holger Michael Zellentin, The Qur'ān's Legal Culture. The Didascalia Apostolorum as a Point of Departure (Tübingen: Mohr Siebeck, 2013), 6-10.

21 Christiaan Snouck Hurgronje, Het Mekkaansche Feest (Leiden: Brill, 1880), 28-40; Christiaan Snouck Hurgronje, «Une nouvelle biographie de Mohammed,» Revue de l'histoire des religions 30 (1894): 64-67; cf. Theodor Nöldeke and Friedrich Schwally, Geschichte des Qorāns, 2nd edition, 3 vols. (Leipzig: Dietrich, 1909-1938), 1:146-147; Theodor Nöldeke, The History of the Qur'ān, ed. and trans. Wolfgang H. Behn (Leiden: Brill, 2012), 119-12O.

22 Ce en quoi il fut critiqué par Charles Cutler Torrey, The Jewish Foundation of Islam (New York: Jewish Institute of Religion Press, 1933), 87, qui cependant qualifie le travail du savant hollandais de «brilliant and searching monograph».

23 Snouck Hurgronje, Het Mekkaansche Feest, 10.

24 Aloys Sprenger, Das Leben und die Lehre des Mohammeds, 3 vols. (Berlin, Nicolaische Verlagsbuchhandlung, 1869; 2ème éd.), 2: 278. Le vol. I fut édité une première fois en 1861. Snouck Hurgronje se réfère aux trois volumes de Sprenger, aux pages suivantes: 14, 26, 30, 49, 58, 63, 66 n. 2, 77, 91, 140, 19o, 196. P. 66, n. 1, Snouck Hurgronje renvoie à «Zeitschrift d. DMG, XIII: 134 vv.», i.e. Sprenger, «Ueber den Kalender der Araber vor Moḥammad,» ZDMG, XIII (1859), 134-175.

25 Sprenger, Leben, sur les hanïfs, 1:43-92; addenda, 107-134; 3: 8-9. Pour le reste $v$. index.

26 Régis Blachère, Le Coran, traduction selon un essai de reclassement des sourates, 3 vols. (Paris: G.P. Maisonneuve, 1947-1951), 664-701; v. ses remarques, p. 664-665.

27 Youakim Moubarac, Abraham dans le Coran. L'histoire d'Abraham dans le Coran et la naissance de l'Islam (Paris: J. Vrin, 1958), 56. Avant lui, Josef Horovitz, Koranische Untersuchungen (Berlin and Leipzig: Walter de Gruyter, 1929), 56: «hanīf se trouve en premier lieu dans la période mecquoise tardive», et de mentionner Q 10:105 et 30:30. 
même pour Q 16:124, qui met en relation millat Ibrāhīm avec hanaiff. De la sorte, on considérera que ce que Muhammad connaissait dès La Mecque des traditions hébraico-juives, en général, et des récits du Pentateuque, en particulier, était bien plus développé que ce que l'on pouvait supposer quelques années avant 1880, ainsi que le remarque Charles Cutler Torrey (1863-1956). ${ }^{29}$ Cette connaissance pouvait être directe, c' est-à-dire déjà présente en arabe, ou être parvenue à Muhammad par la voie araméenne ou syriaque.

On se doit d'évoquer également la variante du codex d' Ibn Mas'ūd en Q 3:19: inna l-dìna 'inda llāhi l-hanāifyyatu, ${ }^{30}$ au lieu de inna l-dìna 'inda llāhi l-islāmu. L' exégète et grammairien réputé Abū Ḥayyān al-Gharnāțī (m. 745/1344) ajoute à cela une remarque d' Ibn al-Anbārī (Abū Bakr Muḥammad b. al-Qāsim, m. 328/940) pour qui: «Il n'échappera pas à qui a du discernement que cette parole provient du Prophète, par mode d'exégèse. L'un des transmetteurs de hadìth l' aura intégrée parmi les lectures coraniques (adkhalahu badu man yanqulu l-hadìtha fì al-qirāàat)».31

Nous ne nous prononcerons pas ici sur cette variante, non plus que sur d'autres, ce serait un autre travail. En effet, il a été montré ailleurs combien le vocabulaire de la «collecte» ou «mémorisation» du Coran (jam 'et jama'a, pour ces deux opérations ou entreprises), ${ }^{32}$ mais aussi de la composition ou coordination $\left(t a^{\prime} l i f f\right)^{33}$ de ce «texte» en voie d'établissement est ambigu à souhait. Certains récits à ce sujet sur des versets «perdus» puis «retrouvés», sur des sourates qui n' auraient pas été écartées du texte dit " 'uthmānien», ${ }^{34}$ sur le fait de savoir ce qui était du Coran et ce qui n' en était point, sont même parfois cocasses, burlesques. ${ }^{35}$

29 Torrey, Jewish foundation, 88, puis 98-99, pour Q 16:123, que Torrey considère mecquois, contre Snouck Hurgronje et Nöldeke-Schwally, Nöldeke, Geschichte, 1: 146-147.

$30 \quad$ Arthur Jeffery, Materials for the History of the Text of the Qur'ān (Leiden: Brill, 1937), 32.

31 Abū Hayyān al-Gharnāțī, Tafsìr al-Bahr al-muhūț, eds. 'Ādil Aḥmad 'Abd al-Mawjūd and 'Alī M. Mu'awwaḍ, 8 vols. (Beirut: Dār al-Kutub al-'ilmiyya, 1993), 2: 426, 2: 1. 15-17.

32 Claude Gilliot, «Collecte, » 77-132.

33 Claude Gilliot, «Les traditions sur la composition ou coordination du Coran (ta'lif alqur'ān),» in Das Prophetenhadīt. Dimensionen einer islamischen Literaturgattung, eds. Claude Gilliot and Tilman Nagel (Göttingen: Vandenhoeck \& Ruprecht, 2005), 14-39. Une version corrigée de cette contribution est déposée sur: https://univ-amu.academia.edu/ ClaudeGilliot.

34 Mohammed Ali Amir-Moezzi and Etan Kohlberg, «Révélation et falsification: introduction à l' édition du Kitāb al-Qirāāāt d' al-Sayyārī,» Journal Asiatique 293, no. 2 (2005): 663722 .

35 Claude Gilliot, «Un verset manquant du Coran ou réputé tel,» in En hommage au Père Jacques Jomier, o.p., ed. Marie-Thérèse Urvoy (Paris: Cerf, 2002), 73-80. 
On ne s' étonnera de trouver une «variante» proche de la précédente, cette fois transmise par Ubayy b. Ka $\mathrm{b}$ dont le codex, d'après ce que nous en savons, était proche de celui d'Ibn Mas'ūd, dans le commentaire coranique de Qurțubī (m. 671/1273): d' après Shu 'ba (b. al-Hajjāj al-Azdī al-'Atakī al-Bașrī, m. rajab 16o/inc. 14 avril 777) ${ }^{36} /$ Āṣim (b. a. al-Najjūd al-Bahdala al-Asadī al-Kūfî, m. 127/745)/Zirr b. Hubaysh al-Kūfí37/Ubayy b. Ka'b (Abū al-Mundhir al-Khazrajī al-Najjārī al-Anșāīi, m. entre 19/640 et 35/656): «Le Prophète récitait: La religion, pour Dieu, c' est le hanīfisme (inna al-dīn 'inda llāh al-hanífiyya), et non le judaïsme, non plus que le christianisme ou le zoroastrisme». Avant Abū Ḥayyān al-Andalusī (m. 745/1344), Qurțubī avait repris la remarque d'Ibn alAnbārī que l' ont vient de voir. ${ }^{38}$

On notera que, après al-Sha'bī ('Āmir b. Sharāhịil al-Kūfì, m. entre 103 et 110/721-728), ${ }^{39}$ 'Āṣim b. a. al-Najjūd, le célèbre expert ès lectiones coranicae, fut le plus ancien Coufien à recourir à un transmetteur macrobite $(\text { múammar })^{40}$, en l'occurrence le mukhaḍram Zirr b. Ḥubaysh b. Ḥubāsha al-Asadī al-Kūfī, Abū Maryam ou Abū Muțarrif, récitateur du Coran (muqri'), tué à la bataille de Dayr al-Jamājim en sha'bān 82/septembre 701, ou à une autre date, lequel est supposé être mort à l'âge de 127,120 , ou autres dates. ${ }^{41}$ On sait que l'âge donné pour la mort d'anciens transmetteurs dépendait souvent du degré de vraisemblance que l'on voulait accorder à des chaînes de garants, pour ce qui est de la «rencontre» (luqya, liqa $\vec{a}$ ), chronologiquement possible ou non, de deux transmetteurs. ${ }^{42}$ On s'évertua donc à trouver de ces macrobites ou à en ériger certains tels.

36 Gautier H.A. Juynboll, «Shu'ba b. al-Ḥadjdjādj, » in Encyclopaedia of Islam, 2nd ed., vol. IX (Leiden: Brill, 1997), 491-492; Gautier H.A. Juynboll, «Shu'ba b. al-Hajjāj (d. 16o/776) and his position among the traditionists of Bașra,» Le Muséon 111 (1998): 187-226; Gautier H.A. Juynboll, Encyclopedia of Canonical Hadith (Leiden: Brill, 2007), 471-566.

37 Sur lui, $v$. infra.

38 Qurțubī, al-Jāmi li-ahkām al-Qur'ān, 2nd edition, eds. Aḥmad 'Abd al-'Alīm al-Bardūnī et Ibrāhīm Aṭ̂yyish, 20 vols. (Cairo: al-Hay’a al-mișriyya al-āmma li-l-kitāb, 1372-1387/ 1952-1967), 4:43.

39 Gautier H.A. Juynboll, «al-Sha'bī, » in Encyclopaedia of Islam, 2nd ed., vol. Ix (Leiden: Brill, 1997), 162-163; Juynboll, Canonical Hadith, 463-471.

40 Gautier H.A. Juynboll, «The Role of the Mu'ammarūn in the Early Development of the isnād,» Wiener Zeitschrift für die Kunde des Morgenlandes 81 (1971): 159, repris dans Gautier H.A. Juynboll, Studies on the Origins and Uses of Islamic Hadith (Aldershot: Variorum, 1996), no. VII.

41 Mizzī, Tahdhīb al-kamāl fì asmā̄ al-rijāl, ed. Bashshār 'Awwād Ma'rūf, 35 vols. (Beirut: Mu’assasat al-Risāla, 1400-1404/198o-1985), 9: 335-339, no. 1976. Les noms de cinq macrobites, ou supposés tels, dont Zirr, figurent dans les sources; Juynboll, Canonical Hadith, $58 \mathrm{a}$.

42 Gautier H.A. Juynboll, Muslim Tradition: Studies on Chronology, Provenance and Authorship of Early Hadith (Cambridge: Cambridge University Press, 1983), 43, 181. 
Parmi les variantes coraniques ou «les prophéties oraculaires ${ }^{43}$ délivrées par Muhammad, comme il plaira, qui ne se trouvent point dans le Coran en l'état que nous lui connaissons ${ }^{44}$, mais qui ressortissent peu prou à notre propos, le «hanīfisme» (al-hanífuyya), il en est une qui est en relation avec la sourate 98 . Elle est introduite par la même chaîne de garants que précédemment. Or donc Muḥammad dit à Ubayy: «Dieu m' a ordonné de te réciter: Point n' étaient les dénégateurs d' entre les gens du livre... (lamyakuni lladhina kafarū min ahli l-kitäbi..., i.e. la sourate qui commence par lamyakun, et qui fut appelée aussi par la suite: al-Bayyina, ou al-Qayyima, etc., sourate 98). [Ubayy] dit: puis [l'Envoyé de Dieu] en récita (qara'a fìhā): Si le fils d'Adam demandait un wāa $\bar{\imath}$ de biens ${ }^{45}$ et qu' il lui était donné, il en demanderait un deuxième; s'il lui était donné, il en demanderait un troisième (law anna bna Ādama sảala wādiyan min mälin fa-u'tiyahu la-sa’ala thāniyan fa-u'tiyahu la-sảala thālithan). Seule la terre remplira le ventre du fils d'Adam. Dieu revient vers qui revient [à lui] (wa yatūbu llāhu 'alā man tāba). ${ }^{46}$ La religion vraie pour Dieu est le ḥanīfisme non associateur, ce n' est ni le judaïsme ni le nazaréisme. Celui qui fait le bien, je ne le renierai pas» (wa inna dhālika l-dīna l-qayyima 'inda llāhil-hanafiyyatu ghayru l-mushrikatiwa lā al-yahūdiyyatu wa lā al-nașrāniyyatu wa man ya'malu khayran fa-lan yukfarahu). ${ }^{47}$

Dans la version rapportée par al-Ḥākim al-Nīsābūrī (m. 405/1014), après le début de la sourate 98, ut supra, on trouve, comme il arrive souvent, une intervention de l'un des transmetteurs: «et autres qualifications» (wa man $n a^{\top}$ taha $)$, quasiment équivalente à et caetera, avant: «Si le fils d'Adam deman-

43 L' expression est de Van Reeth, «Les prophéties oraculaires dans le Coran.»

44 Nöldeke, Geschichte, 1: 234-261/ Nöldeke, History, 189-208. Le titre donné par W. Behn à cette partie est un contresens et un anachronisme: «Muhammad's uncanonical promulgations» (allemand: «Die im Qorān nicht erhaltenen Offenbarungen Muhammeds»). Il fallait traduire: «The revelations of Muhammad which are not contained in the Koran», bien rendu dans la traduction arabe de Georges Tamer, Ta'rīkh al-Qur'ān (Konrad-Adenauer Stiftung, 2005), 210: Mã lā yatadammanuhu l-Qur'ān mimmā ūhiya ilā Muhammad.

45 Al-Ṭayālisī, al-Musnad (Hyderabad: Dāirat al-ma‘āif al-niẓāmiyya, 1321/19o3), 73, no. 539, donne la version suivante de ce passage: «Si le fils d'Adam avait un wādī, il en souhaiterait (la-abtaghā) un deuxième », etc.;Jeffery, Materials, 179 (codex de Ubayy) a seulement, on s' en douterait: inna l-dina 'inda llāhi al-ḥanafiyyatu ghayru l-yahūdiyyati... fal-lan ukfarahu.

46 «Dieu revient vers qui revient» est placé à la fin de la tradition chez Ṭayālisī.

47 Ibn Ḥanbal, Musnad, ed. Muḥammad al-Zuhrī al-Ghamrāwī, 6 vols. (Cairo: al-Maṭba'a alMaymaniyya, 1313/1895), 5:131-132; édition en 2o vols., ed. Aḥmad Muḥammad Shākir, puis al-Ḥusaynī 'Abd al-Majīd Hāshim et 'Umar Hāshim (Cairo: Dār al-Ḥadīth, 1416/1995), 15: 446 , no. 21101. 
dait un wādī... $\gg^{48}$ Suyūṭī (m. 911/1505) déclare citer la tradition du Mustadrak ${ }^{49}$, mais il n' a pas: wa man na'tahā. De plus au lieu de inna l-dìna 'inda llāhi, il a: inna dhāta l-dìni l-hanafiyyatu... ${ }^{50}$, comme dans la version de Tirmidhī.

Que la mention du soi-disant hanīfisme fût importante pour Muḥammad et/ou pour ceux qui l'ont aidé, préparé et encouragé à déclamer de ses oracles, c'est ce que montre bien la variété des traditions à ce sujet, ainsi, une fois encore avec les mêmes hommes qui transmettent de Ubayy: L' Envoyé de Dieu a dit: «Dieu, béni et exalté, m'a ordonné de te réciter le Coran». Et il récita: «Point n'étaient les dénégateurs d'entre les gens du livre et les associateurs déliés (de leur dénégation/ingratitude, $k u f r)^{51}$ tant que la preuve ne leur était venue (Lam yakuni lladhīna kafarū min ahli l-kitābi munfakkīna hattā ta’tiyahumu l-bayyina): un envoyé de Dieu qui récite des rouleaux purifiés contenant des écritures qui perdurent. Ils ne se sont divisés, ceux à qui le Livre a été donné qu' après que la preuve leur fut venue (rasūlun mina llāhi yatlū șuhufan muțahhara/, fìñ kutubun qayyima/, wa mā tafarraqa lladhīna ūtū al-kitāba illā min ba'di mājā̉athumu l-bayyina) »52 (Coran 98: 1-4). Puis il récita de cette sourate $(f i h \bar{a}):$ «a religion pour Dieu est le hanīfisme non associateur, ce n' est ni le judaïsme ni le nazaréisme. Celui qui fait le bien, je ne le renierai pas». Shu'ba dit:Ensuite, il récita des versets après cela, puis il récita: «Si le fils d'Adam avait

48 Al-Ḥākim al-Nīsābūrī, al-Mustadrak 'alā al-Ṣahịhayn fì al-ḥadīth, eds. M. 'Arab b. Muhammad Ḥusayn et al., 4 vols. (Hyderabad, 1334-1342/1915-23), 2: 224, ou ed. Muqbil b. Hādī al-Wādi', Le Caire, Dār al-Ḥaramayn, $2: 269$.

49 Al-Suyūṭī, al-Itqān fì 'ulūm al-Qur'ān ed. Muhammad Abū al-Faḍl Ibrāhīm, 4 vols. en 2 (Cairo: al-Hay’a al-miṣriyya al-āmma li-l-kitāb, 1974-1975), 3: 83, cap. 47.

50 C' est la version de Suyūți qu' a traduite John Burton, The Collection of the Qur'ān (Cambridge: Cambridge University Press, 1977), 82, rendue par: «The very faith in God's eyes is the Hanīiyya».

51 Zajjāj, Ma'ānī al-Qur'ān wa i'rābuh, ed. 'Abd al-Jalīl 'Abduh Shalabī, 5 vols. (Beirut: 'Ālam al-kutub, 1408/1988), 5:349; cf. Țabarī, Annales, eds. Michael J. de Goeje, Jacob Barth, Theodor Nöldeke et al., 3 vols. (in 16 parts) (Leiden: Brill 1879-1901), 1: 2830, l. 1: fa-lā nunfikku min Ash'arī... (N'allons-nous pas nous libérer [ou séparer, nunfikku min] d'un 'Ash'arite [i.e. Abū Mūsā al-Ash`arī]...).

$5^{2}$ La traduction du début de la sourate 98 qui est nôtre suit l' ordre du texte arabe. Nous imitons en cela Friedrich Rückert qui n'a pas traduit cette sourate, mais qui lui avait donné l'un de ses titres qui suit l'ordre de l' arabe: Nicht sind gewesen (Lam yakun). Max Henning eut également recours à l' inversion interrogative: Nicht eherwurden die Unglüubigen. Dénégateur et associateur sont empruntés, pour l' assonance, à J. Berque. Dénégateur a été préféré à incrédule. En effet, dans kafara, il y a l'idée d'ingratitude, de «non reconnaissance d'un bienfait»; Jacqueline Chabbi, Le Seigneur des tribus: l'islam de Mahomet (Paris: Noêsis, 1997), 565 (n. 381 de la p. 259): «ceux qui ont été ingrats (vis-à-vis de Dieu ou les Négateurs), » et p. 603, n. 56o. Ou encore: «recouvrir le bienfait, ni'ma, pour ne pas le voir et se dispenser de la gratitude qui est due»; Jacqueline Chabbi, Les trois piliers de l'islam. Lecture anthropologique du Coran (Paris: Seuil, 2016), 344. 
deux $w a \bar{d} d \bar{\imath}$ de biens, il en demanderait un troisième. Seule la terre remplira le ventre du fils d'Adam». Il dit (i.e. Shu'ba dans sa transmission de la tradition d'Ubayy): «Ensuite il récita jusqu' au bout ce qui restait de la sourate» (thumma khatamahā bi-mā baqiya minhā). ${ }^{53}$

Ce n' est d'ailleurs pas un hasard si la date de la mort de Ubayy b. Kab qui était au nombre de ceux de Yathrib qui savaient lire, ${ }^{54}$ qui fut surnommé par la suite «le seigneur des récitateurs» (du Coran, sayyid al-qurrä) et dont des traditions prétendent qu'il fut l' un des quatre auxiliaires qui «collectèrent» le Coran (ou du coran?), et ce du vivant de Muhammad, ${ }^{55}$ fait problème. En effet, dans l' imaginaire culturel et religieux de l' islam, il fallait qu'il apparût comme une caution des deux «collectes» du Coran après la mort de Muhammad. Le décès de ce «secrétaire» de la «révélation» donc serait survenue sous le califat de 'Umar peut-être en 19/640; pour d' autres sous celui de 'Uthmān, qui aurait dit la prière lors de ses funérailles, en 32/652-653, ou 33, voire $35^{5^{56}}$ En outre, Ubayy est placé en lice parmi ceux qui auraient été nommés pour la première fois cadi $(q \bar{a} d \bar{\imath})$ en islam. ${ }^{57}$

Dans la tradition de Ubayy, chez le karrāmite anonyme du Kitāb al-Mabānī, désormais identifié par Hassan al-Ansari (Farhang) comme étant le karrāmite Ibn Bistām Abū Muḥammad Ḥāmid b. Aḥmad b. Jacfar b. Bisțām al-Ṭahīīī (plus probablement: al-Ṭakhīrī, ob. post 450/1058), ${ }^{58}$ l' on trouve une variante d'importance pour notre propos, à savoir: «[...] et il (Muhammad) en récita (i.e. de la sourate 98 ; qara'a fíha $)$ : La religion pour Dieu est le hanīfisme mitigé (al-hanafiyya al-samha, expression sur laquelle nous reviendrons, infra), ce

53 Ibn Ḥanbal, Musnad, 5:132, 15: 446, no. 21102; Jeffery, Materials, 139: de inna l-dina inda Llāhi... fa-lan yukfarahu; pour d' autres références, $\nu$. Gilliot, «Un verset manquant, » 87, n. 3 .

54 Claude Gilliot, «Die Schreib- und/oder Lesekundigkeit in Mekka und Yathrib/Medina zur Zeit Mohammeds, in Schlaglichter: Die beiden ersten islamischen Jahrhunderte, eds. Markus Groß and Karl-Heinz Ohlig (Berlin: Verlag Hans Schiler, 2005), 308.

55 Juynboll, Canonical Hadith, 479b: Mu'ādh b. Jabal, Ubayy, Zayd b. Thābit et l'énigmatique Abū Zayd, sur l'identité duquel Anas b. Mālik interrogé par Qatāda, répondit: «Un mien oncle paternal décédé,» comme par hasard!

56 Andrew Rippin, «Ubayy b. Kacb, in Encyclopaedia of Islam, 2nd ed., vol. x (Leiden: Brill, 2000), 764 : entre $19 / 640$ et 35/654-655.

57 Juynboll, Muslim Tradition, 77-78.

$5^{8}$ Hasan Anșārī Qummī (Hassan Farhang), in Kitab Mah-i Din (revue de Téhéran), 56-57 (1381 sh.), 8o. Ibn Bistām est le transmetteur direct de l' ouvrage de son maître Abū 'Amr Ibn Yaḥyā al-Muḥtasib (M. b. Yahyyā b. al-Ḥasan b. Aḥmad b. 'Alī al-Nīsābūrī al-Jūrī, m. 427/1036), al-Qawāri' min al-Qur'ān wa mā yustahabb an lā yukhall bi-qirāatih kull yawm wa layla, ed. A. b. Fāris al-Salūm (Riyad: Maktabat al-Macarif, 1432/2011). Nous supposons qu'Ibn Bistām est mort peu après 450/1058. 
n' est ni le judaïsme ni le nazaréisme. Celui qui fait le bien, je ne le renierai pas».59 Une autre variante, est celle que l'on rencontre chez Abū 'İsā alTirmidhī (m. 279/892): «La religion en soi pour Dieu est le hanīfisme inna dhāta l-dīni inda llāhi l-ḥanīfiyyatu l-muslima, lā al-yahūdiyya wa lā al-naṣrā [sic?]».60

Le mot hanif fait partie de ces termes ou expressions coraniques qui ont donné de la tablature aux commentateurs musulmans du Coran et à nous orientalistes. Il n' est pas certain qu'il puisse être rendu par un seul et même vocable, selon le contexte. Tel traducteur a eu recours à deux ou trois termes dans la langue d'arrivée, que cela fût à dessein ou par inadvertance. Nous commencerons par un aperçu de quelques traductions de cette crux interpretum: un croyant «orthodoxe» (orthodoxus, Marracci, 1698: imo sequemur religionem Abrahae Orthodoxi: et non fuit Abraham ex Associantibus) (Q 2: 135); ${ }^{61}$ Marracci fut suivi par George Sale (1734), dont la traduction n' est souvent guère plus que celle du texte latin du religieux italien rendu en anglais, ainsi: «we follow the religion of Abraham, the orthodox, who was no idolater» (Q 2: 135). Du Ryer (1647): «... professe l'unité de Dieu». Pour d'autres: « ein Rechtgläubiger», «rechtgläubig», «andächtig» (Friedrich Rückert, 17881856); ${ }^{62}$ un «vrai croyant» (Albin de Biberstein Kazimirski, 1840; Denise Masson, 1967; Ameur Ghédira, 1957: mais aussi « hananif» ou « hanif»); «upright man», «as one by nature upright», haniffan ad Q 6: 79 (Marmaduke Pickthall, 1930); «true in faith», «pure faith», «firmly and truly», hanīfan Q 6: 79, etc. (Abdullah Yusuf Ali, 1934-1937);63 «droit», «droiture», e.g. «modèle de droiture», pour Abraham (Octave Pesle et Ahmed Tidjani, 1937: ou bien recours à des périphrases); « one of pure faith» ou «a man of pure faith» hanī-

59 Anonymous, Kitāb al-Mabānī, ed. Arthur Jeffery (in Two Muqqadimas to the Qur'ānīc sciences, Cairo: al-Khānjī, 1954), 91.

6o Al-Tirmidhī, al-Jāmi al-șaḥ̄ḥ, eds. Ahmad Muhammad Shākir, Muhammad Fu’ād 'Abd alBāqī and Ibrāhīm 'Ațwah 'Awaḍ, 5 vols. (Cairo: Mușțafā al-Halabī, 1357-1381/1938-1962), 5: 665-666, no. 3793, 711, no. 3898; Ibn Ḥajar al-'Asqalānī, Faṭ̣ al-bārī bi-šarh Șaḥịh alBukhārī, édition et muqaddima Muhibb al-Dīn al-Khațīb, numérotation des traditions de Muḥammad Fu'ād 'Abd al-Bāqī, 13 vols. (Cairo: al-Mațba'a al-salafiyya, 1379-139o/196o1970), 81 (Kitāa al-Riqāq), cap. 10, ad. no. 6440, 11: 257 .

61 Alcorani Textus Universus [...] in Latinum translatus appositis notis atque Refutatione. His omnibus praemissus est prodromus auctore Ludovico Marraccio (Patavii : ex typographia Seminarii, 1698): 59 (versiculus 136, apud Marracci).

62 Friedrich Rückert, Der Koran, in der Übersetzung von Friedrich Rückert, third edition, ed. Hartmut Bobzin (Würzburg: Ergon, 2000). Il y manque la traduction des sourates 85-9o, 98. Certaines sourates ne sont que partiellement traduites, e.g. sourates $27,30,33,37,40$, 42, etc.

63 Reynolds, The Qurāan, 75, n. 174 (75-87, pour hanīf). 
fan Q 6: 79 (Arberry, 1955) ${ }^{64}$; croyant sincère, «monothéiste convaincu», ou «monothéiste sincère» (Si Hamza Boubakeur, 1972); «croyant authentique», «pur monothéiste», «[Abraham] qui n' adora que Dieu seul» (Sadok Mazigh, Paris, 1985, deuxième édition; Tunis, 1980); «croyant originel» (Berque, 1990); «upright man», «upright», «uprightly», en Q 3: 37 «hanif » (Fakhry, 1996); «ein aus innerstem Wesen Glaubender» (Hans Zirker, 2003); «pure faith», «true believer», «upright», etc. (Abdel Haleem, 2004) ${ }^{65}$. Ont choisi hanīf (ou autre orthographe): Edward Henry Palmer (1880, avec en note I, 19: «inclining to what is right»), Régis Blachère (1949-1950), Rudi Paret (1966), Seyyed Hossein Nasr et al. (2015).

De leur côté, les sources lexicales arabes tendent à considérer que le sens originel de haniff est «pencher», «incliner d'un côté plutôt que d'un autre». C' est ainsi que le lexicographe, exégète et spécialistes des lectures coraniques Abū Manșūr al-Azharī (m. 370/98o, né et mort à Hérat) renvoie en première place dans sa notice $H N F$ à al-Layth (b. Muzaffar, ob. ca. 190/805) ${ }^{66}$, pour le nom al-hanaf: «le fait d' avoir la plante des pieds contournée» (al-hanafu maylun fi șadri l-qadami); on parlera alors de «pied bot, pied bot équin, pied bot varus» (al-rijlu l-hanfäu, equinovarus deformity), ou d'un «homme au pied bot» (rajulun ahnafu); un homme cagneux ou bancal, un cheval cagneux (qui a les jambes ou les genoux tournés en dedans. Le latin valgus est réservé à un membre ou à un segment de membre qui présente une forme déviée en dehors). ${ }^{67}$ Pour ce qui est du deuxième sens principal de la racine, al-Azhari se réclame pareillement d'al-Layth: al-hanīf c' est «le muslim qui se tourne en direction de la Maison sacrée, conformément à la religion d'Abraham. C'est un muslim ${ }^{68}$ Mais il renvoie aussi à l' exégète bassorien, très lettré en arabe et spécialiste de poésie arabe ancienne, Abū 'Ubayda Ma'mar b. al-Mutannā alTaymī (m. 206/821), ad Q 2:135: «Non point! [suivez] la religion d' Abraham, un hanīf » (balmillata Ibrähìma ḥanīfan): «qui adhère à la religion d'Abraham est hanīf $»$. En fait l' interprétation complète du Bassorien est la suivante: «al-ḥanîf à l'époque de l'ignorance était celui qui adhérait à la religion d' Abraham. Puis

64 Reynolds, The Qur'ān, 76, place A.J. Arberry parmi ceux qui ne traduisent pas ce terme, ce qui n' est pas le cas.

65 Reynolds, The Qurāan, 75, n. 176, note que Abdel Haleem est le moins constant dans sa traduction de hanīf.

66 Comme on le sait, Abū Manșūr al-Azharī, mais d' autres également, considérait que la plus grande partie du Kitāb al-'Ayn était le fait, non pas d'al-Khalīl b. Aḥmad al-Farāhīdī (m. 16o/717 ou 175/791), mais d' al-Layth.

67 Abū Manșūr Muhammad b. Aḥmad b. al-Azhar al-Harawī al-Shāfí̄ Al-Azhari, Tahdhīb al-lugha, ed. 'Abd al-Salām M. Hārūn, et al. (Le Caire: al-Mu'assasa al-mișriyya al-'amma li-al-ta'lif, et al., 1384-1387/1964-67), 5: 109b. al-Azharī, Tahdhīb al-lugha, 5: 110a. 
on désigna sous le nom de hanäf celui qui était circoncis et qui faisait le Pèlerinage à la Maison. Puis les années se succédèrent et ceux des Arabes qui adoraient les idoles continuèrent à dire: nous adhérons à la religion d'Abraham, mais en fait, ils n' observaient de cette religion que le pèlerinage à la Maison et la circoncision. De nos jours, le hanīf, c' est le musulman.» ${ }^{69}$

Le lexicographe, originaire de la province de Faryāb, al-Jawharī (ob. 393/1003 ou ca. 400/1009) donne en premier lieu «le fait d'avoir le pied tordu» (al-i'wāj fi l-rijl), puis al-muslim («le musulman»). «C' est ainsi que le droit (celui qui suit la voie droite) fut appelé» (wa qad summiya l-mustaqìmu bi-dhālika). ${ }^{70}$

L'Andalou Ibn Sīda (m. 458/1066) distingue clairement dans la notice de l'un de ses dictionnaires entre «la distorsion des deux pieds» (al-hanaf fi lqadamayn) ou «une déformation de la plante du pied» (maylun fi șadri lqadami), et autres descriptions analogues, du sens religieux islamisé: al-haniff est «le muslim qui se détourne des religions, à savoir celui qui se tourne vers la vérité. On dit également que c' est celui qui se se tourne en direction de la Maison [sacrée], conformément à la religion d'Abraham ».

Le lexicographe, né à Lahore, al-Ṣaghānī (Raḍi al-Dīn al-Ḥasan b. M., m. $650 / 1252)$ débute aussi sa notice par «le fait d' avoir le pied tordu» (al-i'wājfílrijl), puis reproduit la citation d' al-Layṭh qui se trouvait déjà chez al-Azharī. Ibn Manẓūr appelé aussi Ibn al-Mukarram al-Ifrīqī (m. 711/1311) commence aussi par «le fait d'avoir la plante des pieds contournée.$^{71}$

Toutefois, on se gardera d'oublier que les dictionnaires arabes musulmans sont tous «coranisés», i.e. largement conditionnés par les interprétations cléricales des exégètes, juristes et théologiens. D' ailleurs les « lexicographes» sont le plus souvent également des «juristes-théologiens», et vice-versa. Dès lors, on ne sera pas étonné de ce que l'auteur du Tāj al-'arūs, Murtaḍā b. Muḥammad al-Zabīdì (originaire du Nord-Ouest de l'Inde, m. au Caire, en 1205/1791) ait commencé la notice HNF par al-ḩanafu: al-istiqāmatu (le fait d'être droit). Il faut dire, à sa décharge, qu'al-Fīrūzābādī (M. b. Ya'qūb, m. 872/1415) avait ouvert sa propre notice par: (1) al-hanafu: al-istiqāma, (2) al-i'wāj fi l-rijl. ${ }^{72}$ Zabīdī, dont le dictionnaire est construit sur la base du Quamūs de Fīrūzābādī, renvoie en plus au commentaire d' Ibn 'Arafa (m. 803/1401) ad Q 2: 135: «Non

69 Abū 'Ubayda. Majāz al-Qur’ān, ed. Fuat Sezgin, 2 vols. (Cairo : al-Khānjī, 1954-1962), 1: 58. Traduit, en partie, en anglais, in Lane, An Arabic-English lexicon, 2 vols. (Cambridge: Islamic Texts Society Trust, 1984), 1: 658b.

70 Abū Nașr al-Jawharī, al-Ṣihạhh, ed. A. 'Abd al-Ghafūr 'Aț̣āār (Cairo: Mațābi' Dār al-K. al-K. al-'arabī, 1376-1377/1956-57), 4: 1347a.

71 M. b. al-Mukarram Ibn Manẓūr, Lisān al-'Arab, 15 vols. (texte repris de l'éd. de Boulac, 1882189o; Beyrouth: Dār Șādir, 1955), 9: 56a. 
point! [suivez] la religion d'Abraham, un hanīf qui ne fut point parmi les associateurs»: «On dit ahnafu (ici devant être compris comme: droit, sic!) pour augurer du bien (ou par euphémisme) à celui qui a un pied bot (tafẳulan biistiqāmati).» ${ }^{73}$ Les autres sens donnés à hanīf dans les sources lexicales ont été relevés notamment par $\mathrm{S}$. Bashear, nous ne les reprendons pas ici en détail: celui qui pratique le pèlerinage, le circoncis, etc. ${ }^{74}$

On corrigera la faute de lecture de quelques chercheurs qui leur a fait voir en Mani un hanīf! L'un d'entre eux écrit: «il était le plus hanîf des hommes (kāna aḥnaf al-rağul)», et de se référer à Ibn al-Nadīm. ${ }^{75} \mathrm{Il}$ faut évidemment lire: kāna ahnnafa l-rijli, i.e. il avait un pied déformé, ou une jambe déformée. Un autre commet la même erreur: «The most hanīf of men», mais en ajoute une seconde: ahnaf al-rijäl (sic), ${ }^{76}$ corrigeant ainsi Bayard Dodge, qui avait bien lu (kāna aḥnafa l-rijli) et convenablement traduit: «He, moreover, had a deformed foot». ${ }^{77}$ Dès 1862, mais bien avant certainement, la question avait été réglée par G. Flügel, de vénérée mémoire, qui avait compris que Mani: «litt an einem einwärtsgedrehten Bein» (souffrait d'une jambe tournée vers l'intérieur). ${ }^{78}$

Une ambiguïté a subsisté à propos de l'emploi et du sens de hanīf, notamment dans la littérature polémique entre chrétiens et musulmans, ainsi dans

73 Zabīdī, Muhammad Murtạ̣ā, Tāj al-'arūs min jawāhir al-Qāmūs, eds. 'Abd al-Sattār Aḥmad Farāj et al., 40 vols. (Koweït: Wizārat al-I'lām, 1385-1422/1965-20o1), 23: 168. Nous n' avons pas trouvé ce passage ad loc. (ad Q 2, 135, ou Q 3,67) dans Ibn 'Arafa, Tafsìr alQur'ān, ed. Jalāl al-Asyūṭī, 4 vols. (Beirut: Dār al-Kutub al-ilmiyya, 20o8), 1: 173 (ad Q 2: 135), 370 (Q 3:37).

74 S. Bashear, « Ḥan̄ifiyya and ḥājj, » in Studies in Early Islamic Tradition (Jerusalem: Hebrew University, 2004), 2-8. P. 5, on corrigera le nom de l' informant tel que donné par S. Bashear. Il n' est pas: «Thābit b. Qatāda», non plus que «Thābit b. Qațla» (ainsi dans l'édition de Ibn Durayd, Jahmarat al-lugha, II, 178a, l. 16-17), mais bien le combattant de la guerre sainte et poète murji'ite Thābit Quṭna, i.e. Abū l-Alā' Thābit (b. 'Abd al-Raḥmān) b. Ka'b al-'Atakī des Asad b. al-'Atīk (tué au combat contre les Turcs. 110/726, près de Amul; GAS, 2: 376-377; Van Ess, $T G, 1: 166-171$ ), qui transmet l'information de son père, lequel la tenait (comme par hasard!) de deux témoins, en l' occurrence deux vieillards: quand les gens de Oman voulaient faire le pèlerinage dans la période préislamique: «Allons faire comme des hanīfs (hallumū natahannaf).»

75 Alfred-Louis de Prémare, «'Comme il est écrit'. Histoire d'un texte, Studia Islamica,» 70 $(1989): 46$.

76 Gil, «The Creed of Abū 'Āmir,» 17.

77 Abū l-Faraj M. b. a. Ya'qūb Ibn al-Nadīm, The Fihrist of al-Nadīm. A Tenth-Century Survey of Muslim Culture, ed. and trans. Bayard Dodge (New York: Columbia University Press, 1970), $2: 773$.

78 Gustav Flügel, Mani, seine Lehre und seine Schriften. Aus dem Fihrist des Abû'lfaradsch Muḥammad ben Isḥak al-Warrâk, bekannt unter dem Namen Ibn Abî Jakûb an-Nadîm [...] (Leipzig: Brockhaus, 1862), 83 et 10o, avec n. 282. 
l'épître de 'Abd al-Masị̄ b. Isḥāq al-Kindī au musulman 'Abd Allāh al-Hāshimī (tous deux contemporains du calife al-Ma'mūn, reg. 198-218/813-833). hanīf, haniffyya y apparaissent plusieurs fois, ainsi: «Quand Abraham crut en Dieu et à sa promesse, cela lui fut imputé à justice. Il renonça au hanīfisme qui est le culte des idoles (wa zalla 'ani l-hanafiyyati llatì hiya 'ibādatu l-aṣnāmi) et il devint croyant monothéiste (wa-șāra muwahhịidan mu'minan). Nous trouvons, en effet, «le ḥanīfisme» dans les livres révélés par Dieu pour désigner le culte des idoles (li-annanā najidu l-hanīfiyyata fì kutubi Llähi l-munazzalati sman li'ibādati l-așnāmi).» Et notre auteur d'ironiser sur son adversaire musulman pour qui l' islam est al-din al-hanîf!

Le terme hanîf était employé dans certaines traductions du Nouveau Testament, ainsi ad Mt 10: 5: lā taslukü fì sabïli l-ḥunafäì... (Ne prenez pas le chemin des païens et n' entrez pas dans une ville des Samaritains). ${ }^{79}$ On y reconnaîtra

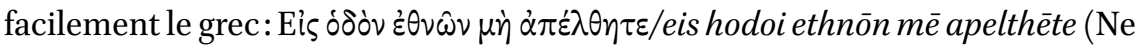
prenez pas le chemin des païens).

Des opinions anciennes à de plus récentes concernant les ḥanīfs

Dans un article qui fit date, publié en 1940 par N.A. Faris (m. 1968) et H.W. Glidden (m. 1990) sur le développement et la signification du terme coranique hanīf, ${ }^{80}$ on a distingué cinq catégories d'opinions pour ce qui est des hanäfs: 1) ils étaient une secte chrétienne ou juive; 2 ) ils n'étaient pas une secte et n' avaient pas de culte spécifique; 3 ) ils représentaient un mouvement sous influence chrétienne ou juive; 4) ils représentaient un mouvement arabe indépendant; 5) ils étaient très liés au sabéens. ${ }^{81}$. Nous avons quelque peu corrigé ailleurs l'assignation par ces deux auteurs de tel ou tel chercheur à l'un de ces groupes. ${ }^{82}$

79 Cité par M. Levy-Rubin, «Praise or defamation?, » 207, d' après G.B. Marcuzzo, Le Dialogue d'Abraham de Tibériade avec 'Abd al-Rahmmān al-Hāshimì à Jérusalem vers 820 (Rome: Pont. Istituto Orientale, 1986), 319. Auparavant dans la traduction allemande de Karl Vollers, «Das Religionsgespräch von Jerusalem (um 800 D.), » aus dem Arabischen übersetzt. ZKG (Zeitschrift für Kirchengeschichte) 29 (1908): 40 (pour l' ensemble: 29-71, 197-221).

8o Nabih Amin Faris and Harold Walter Glidden, «The Development of the Meaning of Koranic Hinīf,» Journal of the Palestine Oriental Society 19 (1939-1940): 1-13; repris dans Rudi Paret (trans.), Der Koran (Darmstadt: Wissenschaftliche Buchgesellschaft, 1975), 255-268. Nous citons ici d' après cette réimpression.

81 Paret, Koran, 255-256.

82 Claude Gilliot, «Muhammad, le Coran et les contraintes de l'histoire,» in The Qur'ān as Text, ed. Stefan Wild (Leiden: Brill, 1996), 6-17. 
Faris et Glidden eux-mêmes, se basant sur des inscriptions et sur la poésie antéislamique, pensaient que: «le hanîf coranique avec tout ce qu'il implique doit provenir (must have come) par la voie de l'arabe préislamique du dialecte des Nabatéens, dans la langue desquels il signifiait un adhérent d'une branche de leur religion syro-arabe partiellement hellénisée ». ${ }^{83}$ Bien que cette hypothèse soit quelque peu du domaine de la spéculation, elle a pu paraitre tentante à certains; ${ }^{84} \mathrm{~d}$ 'autres l'évoquent sans pour autant la retenir comme étant à l'origine du hanīf coranique ${ }^{85}$, ou la qualifient de «solution la plus curieuse à ce jour» ${ }^{86}$ Récemment, dans une contribution quelque peu polémique contre «la conception erronée fallacieuse de l'étymologie dans les études coraniques», Walid Saleh a rappelé cette possibilité, entre autres, sans la reprendre à son compte pour autant. ${ }^{87}$

\section{4 Étymologie(s) du vocable hanāif et emplois coraniques. De l'analogie ou contamination linguistique}

Le Coran a vu le jour dans un milieu et à une époque dans lequels les idées circulaient, et le syncrétisme y était on ne peut plus répandu. Ainsi que l'a écrit Guy Stroumsa: «Nous savons maintenant que l'Arabie était devenue en quelque sorte, à la fin du sixième siècle, une plaque tournante du ProcheOrient, entre l'empire des Sassanides et celui des Byzantins, sans oublier le royaume chrétien d'Axoum, comme nous le rappelle Glen Bowersock. ${ }^{88}$ En Arabie, moines, dissidents, missionnaires, soldats, refugiés et marchands pouvaient permettre, entre autres, la libre circulation des idées religieuses $\gg .89$

83 Faris et Glidden, « Koranic hanīf, » 267 (dans l' original du Journal of the Palestine Oriental Society, 19).

84 Frederick Mathewson Denny, «Some Religio-Communal Terms and Concepts in the Qur'ān,» Numen 24 (1977): 27, n. 7: «Although this is somewhat speculative, the possibility is tantalizing».

85 William Montgomery Watt, Mahomet à La Mecque, trans. François Dourveil (Paris: Payot, 1977), 205-206; W. Montgomery Watt, «Ḥanīf,» in Encyclopaedia of Islam, 2nd ed., vol. III (Leiden: Brill, 1971), 166; Rippin, « R H MNN and the ḥanîfs, » 167.

86 Sirry, «Early development, » 347-348.

87 Walid Saleh, «The Etymological Fallacy and Qur’anic Studies: Muhammad, Paradise, and late Antiquity,» in The Qur'ān in Context: Historical and Literary Investigations into the Qur'ānic Milieu, ed. Angelika Neuwirth (Leiden: Brill, 2010), 66o, n. 32.

88 Glen W. Bowersock, The Throne of Adulis: Red Sea wars on the Eve of Islam (Oxford: Oxford University Press, 2013).

89 Guy G. Stroumsa, «Jewish Christianity and Islamic Origins,» in Islamic Culture, Islamic 
Quant à celui qui occupa de 1991 à 2008 la chaire d'Histoire des syncrétismes de la fin de l'Antiquité, Michel Tardieu, il a pu écrire, non sans raison: «L'hénothéisme universalisant qui s' exprime dans les professions de foi abrahamites du paganisme grec a son aboutissement sémitique dans les représentations coraniques de la millat Ibrâhîm $(2,135 ; 3,95 ; 4,125 ; 6,161 ; 16,123)$ comme hanîfiyya (litt. «paganisme»)».90

Comme l'a rappelé récemment Mun'im Sirry, à la suite de Clare Wilde et Jane Dammen McAuliffe, ${ }^{91}$ l' une des grandes questions est de savoir comment concilier les usages apparemment contradictoires entre le haniff coranique et le hanpā syriaque. Or à y regarder de plus près, il semblerait que hanăf dans le Coran pourrait avoir deux significations contradictoires, voire plus. ${ }^{92} \mathrm{Il}$ ressortirait donc dans ce cas à la catégorie de l'énantiosème (signifiant contradictoire selon Roland Barthes) ou mot énantiosémique (du grec ancien èvavtios, enantíos, «opposé », arabe: $\underline{d i d d}$, pl. adddād). ${ }^{93}$ On sait que pour al-Mas'ūdī hunafăa (haniff) « est un mot syriaque qui a été arabisé (kalima suryāniyya 'urribat)»; il l'emploie dans le sens de «païen.$^{94}$

À l'issue de son enquête sur le Coran, ${ }^{95} \mathrm{M}$. Sirry distingue quatre catégories de gens ou idées:1) celui qui adhère à une religion pure et réelle, 2) la religion naturelle elle-même, 3) une description de la religion d'Abraham vue comme la vraie religion, 4) des gens qui ne sont ni juifs ni chrétiens. ${ }^{96}$

Contexts: Essays in Honour of Professor Patricia Crone, eds. Asad Q. Ahmed, Behnam Sadeghi, Robert G. Hoyland and Adam Silverstein (Leiden: Brill, 2015), 79.

$90 \quad$ Michel Tardieu, «Histoire des syncrétismes de la fin de l'Antiquité: le concept de religion abrahamique, » Annuaire du Collège de France 106 (2005-2006): 439.

91 Clare Wilde and Jane Dammen McAuliffe, «Religious Pluralism in the Qur’ān,» in Encyclopaedia of the Qur'ān, vol. 4 (Leiden: Brill, 2004), 402a: «the tension between the apparent Qur'anic meaning and the close Syriac cognate [...] has yet to be explained satisfactorily, particularly with regards to its usage in a Muslim framework.»

92 Sirry, Early Development, 346.

93 Salim S. al-Khamash, Aḍād: A Study of Homo-Polysemous Opposites in Arabic (PhD diss. Bloomington: Indiana University, 1991); Lidia Bettini, « Didd,» in Encyclopedia of Arabic Language and Linguistics, vol. 1 (Leiden: Brill, 2006), 626-629. Pour les informations données par les lexicographes et les exégètes musulmans, on se référera à Bashear, «Ḥanīfiyya and Hajj, » 2, 3-8; pour les exégètes, à Sirry, «Early Development, » 655-664.

94 Al-Mas'ūdī, Bibliotheca Geographorum Arabicorum. Vol. 8: kitāb al-tanbīh wa-l-ishräf, ed. Michael J. de Goeje (Leiden: Brill, 1894), 90, 122 sq., 136 (kānū 'alā dìn al-șābia wa hiya lhanafiyya), et glossaire/Maçoudi, Le livre de l'avertissement et de la revision, trans. B. Carra de Vaux (Paris: Imprimerie nationale, 1896), 130-132, 171, 189 traduit: «la religion des Sabéens qui est le paganisme primitif»; $v$. à ce sujet les remarques critiques de Watt, «Ḥanīf,» 166.

95 Sirry, «Early Development, » 369-365.

96 Sirry, «Early Development, » 366, ou dans une formulation légérement différente, 355. 
Ce que nous disions plus haut de l'ambiance syncrétiste dans laquelle le Coran s' est progressivement créé prend également tout son sens sur le plan de la langue, si l'on fait appel au phénomène de l' analogie linguistique, appelée aussi contamination linguistique. On entend par contamination linguistique: une «action exercée par un élément sur un autre élément (...) de façon à réaliser un croisement». ${ }^{97}$ Par exemple, la construction «se rappeler de quelque chose» (incorrecte) résulte de la contamination de «se souvenir de quelque chose» (correcte) et de «se rappeler quelque chose» (correcte). Ou bien, sans faire intervenir les notions d' anomalie ou d' incorrection, on entendra l' analogie linguistique comme «Action assimilatrice qui fait que certaines formes changent sous l'influence d' autres formes auxquelles elles sont associées dans l'esprit et qui détermine des créations conformes à des modèles préexistants $\gg .98$

C'est ce phénomène d' analogie ou de contamination linguistique qu'a très bien décrit, sans en employer la terminologie, le Père Paul Joüon, s. j. en étudiant le rapport entre l'hébreu hanēêf, le syriaque hanpā et l'arabe hanäf. «En hébreu, en araméen juif et en syriaque, la racine hnff présente des sens assez variés, mais tous, soit les sens très généraux, soit les sens plus particuliers, ont une nuance péjorative ${ }^{99}$ Et l'insigne sémitisant qu'il fut de remarquer que hanîf, au contraire, «désigne tantôt le païen, tantôt le vrai croyant et notamment le sectateur de la religion d'Abraham». Ces emplois peuvent paraitre contradictoires. Pourtant ils «s' expliquent aisément si l'on considère le sens premier de la racine en arabe, qui est 'inclinare, declinare'». Ce sens premier de la racine h̆nf n' existe plus qu'en arabe, mais il permet de rendre compte des divers sens de l'hébreu et de l'araméen. En hébreu biblique, comme le montre le Père Joüon, hanēef signifie toujours «pervers» ou «dépravé», donc qui incline (du mauvais côté) (declinare). «De l'idée de 'perversion', 'dépravation', on est passé à celle de 'corruption, souillure', usuelle dans le verbe». Quant au hanīf, il est à proprement «celui qui se détourne», selon qu'il se détourne de la vraie religion ou de l'idolâtrie, ce sera alors un «païen» ou un «croyant $» .{ }^{100}$

97 Jules Marouzeau, Lexique de la terminologie linguistique (Paris: P. Geuthner, 1933), s.v.

98 Pris de: Encyclopedie Universelle, «Analogie,» online access through: http://encyclope die_universelle.fracademic.com/807/ANALOGIE [last accessed 1 May 2018].

99 Paul Joüon, «Y Yoxpırns dans l'Évangile et hébreu hanef,» Recherches de sciences religieuses $20(1930): 315$.

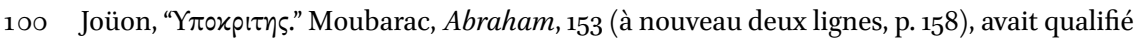
l' explication de Joüon d' ingénieuse, mais sans l' exposer suffisamment. Elle est quasiment restée lettre morte dans la recherche. 
Lu avec des yeux autres que ceux de la foi, le style du Coran paraît tout sauf clair, ${ }^{101}$ et l' on pourrait dire la même chose de son vocabulaire. Cela est dû en partie au grand nombre de mots d'origine étrangère qui s'y trouvent et aux nouvelles significations qui ont été mises à contribution par son auteur ${ }^{102} \mathrm{ou}$ par ses collaborateurs.

Les particularités syntaxiques et lexicographiques, ainsi que «la prépondérance des formules rhétoriques», ces dernières faisant partie de son arsenal argumentatif assez singulier, font du Coran un texte assez «incomparable ». ${ }^{103}$ Nous ne disons pas «inimitable», car nous n'adhérons pas au dogme de son «inimitabilité », i j jāz.

Les vocables hanīf et $u m m \bar{\imath}^{104}$ font partie de ces mots-là du Coran qui font problème. Tous deux ont en commun, à l' origine, l'idée de gentilité (ici, paganisme; nations non juives גוים/goyim/ethnoi). Une fois fois passés en arabe, dans le Coran ou peu avant lui, ils représentent une illustration du phénomène que les linguistes appellent analogie ou contamination linguistique.

Dans le cas de hanīf, on est passé dans le Coran du sens originel du hanpā syriaque (e.g. Abrāhām ḥanpā/Ibrāhìm ḥan̄ff, un païen de naissance, mais non idolâtre $)^{105}$, à un sens laudatif en arabe, «incliner au bien», donc secundum quid «monothéiste» (muwaḥhid).

Pour ce qui est de ummī, nous sommes également en présence d'une analogie ou contamination linguistique: passage de gentil/païen à illettré.

101 Gerd-R. Puin, «Observations on Early Qur'ān Manuscripts in Șan'ä’,» in The Qur'ān as Text, ed. Stefan Wild (Leiden, Brill, 1996), 107: «much of the text... is... far from being as mubin («clear») as the Qurān claims to be!» John Wansbrough, Quranic Studies. Sources and methods of Scriptural interpretation (Oxford: Oxford University Press, 1977), 1, remarque, que la sourate de Joseph (12), souvent présentée comme un exemple unique de récit complet et continu dans le Coran, est tout, sauf claire (is anything but clear), sans le recours à une exégèse. Cela est dû en partie au fait que ce récit est elliptique et comporte des allusions à la tradition extra-biblique.

102 Hartwig Hirschfeld, New Researches into the Composition and Exegesis of the Qoran (Londres: Royal Asiatic Society, 1902), 7 : «If the revelations were delivered in 'plain Arabic' and yet many of them remained unintelligible, this was evidently designed as a further proof to their divine origin. The dogmatic portions in particular continue obscure, owing chiefly to the large number of foreign words and new meanings pressed into service.»

103 Mondher Sfar, Le Coran est-il authenthique? (Paris: Les Éditions Sfar, 2000), 101.

104 Pour ummī appliqué à Muhammad, v. supra sub II; Gilliot, «Schreib- und/oder Lesekundigkeit, » 297-303.

105 Cristoph Luxenberg, The Syro-Aramaic Reading of the Koran (Berlin: Hans Schiler, 2007), 56 ; cf. Rm 4: 9-12; Jc 2: $2:$ Gn 15:6. 
Dans les deux cas, la transformation du sens a été mise au service d'un theologoumenon, à savoir le monoprophétisme du Coran et de l'islam, avec ses corollaires, à savoir les mythes de la religion des origines (dès le proto-homme mythique, Adam, considéré lui-même comme un prophète) et de la religion abrahamique (à La Mecque).

Le recours à l'étymologie n' est pas forcément un traquenard, si l' on y joint le nécessaire recul scientifique et qu' on n' est pas trop sous l'emprise de la bigoterie; Dame Philologie n' est pas de soi «fallacieuse». Elle révèle souvent des choses qu' un livre «révélé » voudrait cacher ou plonger dans le mystère.

Mais laissons le meilleur pour la fin: et si le mystérieux Allāh al-ṣamad $\left(\mathrm{Q} 112^{106}: 2\right)$ n' avait été à l' origine que «le Dieu à la Massue» mentionné dans le mythe ougaritique de Baal ( $b$ l șmd: le Baal/Seigneur à la Massue ou selon Franz Rosenthal: « $b^{c} l$ as the owner of the divine club») ? C' est en tout cas ce que suggère avec quelque vraisemblance notre collègue Mondher Sfar dans un ouvrage, ô combien rafraîchissant. ${ }^{107}$. Il s' est appuyé pour cela sur le savant ès sciences bibliques qu' est Mark Stratton Smith. Ce dernier met en relation une inscription ougaritique avec la célèbre stèle d' Ougarit qui se trouve au Louvre et qui est parfois appelé le «Baal aux foudres». ${ }^{108}$ Le mot șmd de l' ougaritique a parfois été rapproché de l'arabe șamada qui veut dire frapper. ${ }^{109}$ Ainsi selon Abū Zayd, c' est-à-dire Sa'īd b. Aws b. Thabit al-Anșārī, appelé Abū Zayd alNahwī (m. 215/83o, descendant de Zayd b. Thābit, secrétaire de Muhammad): «al-șamd est le fait de frapper (al-ḍarb). On dit: il l'a frappé violemment avec le bâton (yuqālu: șamadahu bi-l-'asâ șamadan) et il lui a donné du bâton (wa șamalahu), s'il l' a frappé avec (idh ḍarabu bihā).»110

Le regretté Franz Rosenthal avait déjà remarqué tout cela, comme le souligne M.S. Smith. En effet, sa contribution est très complète et très fouillée, mais elle n' a pas retenu tout l' attention quelle méritait. Il avait bien vu que le șamad du Coran était: «a survival of a Northwest Semitic religious term ». ${ }^{111} \mathrm{Il}$ avait en tête

106 Les savants musulmans, dont Fakhr al-Dīn al-Rāzī, sont allés jusqu' à donner vingt noms à cette sourate. Pour ce qui est de quelques traducteurs: Bekenntnis der Einheit (Frierich Rückert) Le Culte (Blachère), La Pureté (Hamidullah; devenu: Le Monothéisme pur, dans la traduction de Hamidullah révisée pour le Complexe Roi Fahd sic!), La Profession de foi (Ameur Ghédira).

107 Mondher Sfar, L'autre Coran (Paris: Editions Sophonisbe, 2016), 35, no. 13.

108 Mark S. Smith, The Ugaritic Baal Cycle, 1, Introduction with Text, Translation and Commentary of KTU I.I-I-2 (Leiden: Brill 1994), 338-341.

109 Smith, Ugaritic Baal Cycle, 338.

110 al-Zabīdī, Tāj, 8: 295a.

111 Franz Rosenthal. «Some Minor Problems in the Qur'an,» in The Joshua Starr Memorial Volume. Studies in History and Philology, Jewish Social Studies Publications 5 (New York, 
que l'inscription phénicienne Kilamu sur laquelle il se basait était un témoin ougaritique et phénicien. ${ }^{112}$

On ne s'étonnera pas que Mondher Sfar ait pu écrire à propos de l'élaboration progressive du Coran: «Il est même bien probable que nous soyons ici en présence d'une école scribale qui avait perfectionné depuis des générations ce genre de rhétorique et qui aurait contribué à mettre en forme le discours coranique apportées par Muhammad, à moins que celui-ci n' ait été lui-même membre d' une telle corporation avec laquelle il aurait - ou non - continué à collaborer lors de son apotolat. $»^{113}$

Dame Philologie est loin de craindre le chômage!

\section{Bibliography}

Anonymous. «Kitāb al-Mabānī.» In Two Muqqadimas to Qurānic Sciences, edited by Arthur Jeffery. Cairo: al-Khānjī, 1954.

Abū 'Ubayda, Ma'mar b. al-Muthannā al-Taymī al-Bașrī. Majāz al-Qur'ān. Edited by Fuat Sezgin. 2 vols. Cairo: al-Khānjī, 1374-1382/1954-62.

Abū Ḥayyān al-Gharnāțī, Tafsìr al-Bahr al-muhịt. Edited by 'Ādil Aḥmad 'Abd al-Mawjūd and 'Alī M. Mu'awwaḍ. 8 vols. Beirut: Dār al-Kutub al-'ilmiyya, 1993.

Amir-Moezzi, Mohammed Ali, and Etan Kohlberg. «Révélation et falsification: introduction à l'édition du Kitāb al-Qirāāāt d'al-Sayyārī.» Journal Asiatique 293, no. 2 (2005): 663-722.

al-Azharī, Abū Manșūr Muhammad b. Aḥmad b. al-Azhar al-Harawī al-Shāfiì. Tahdhīb al-lugha. Edited by 'Abd al-Salām M. Hārūn, et al. 17 vols. Cairo: al-Mu’assasa al-mișriyya al-'amma li-al-ta'liff, 1384-1387/1964-67.

Bashear, Suliman. «Hanīfiyya and Hajj.» In Studies in Early Islamic Tradition edited by Suliman Bashear, XIV, 1-21. Jerusalem: The Hebrew University, 2004.

Bettini, Lidia. «Didd.» In Encyclopedia of Arabic Language and Linguistics, vol. 1, edited by Kees Versteegh 626-629. Leiden: Brill, 2006.

Blachère, Régis. Le Coran, traduction selon un essai de reclassement des sourates. 3 vols. Paris: G.P. Maisonneuve, 1947-1951.

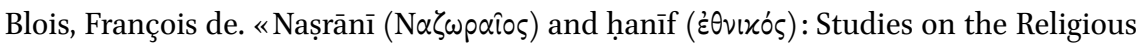
Vocabulary of Christianity and of Islam.» Bulletin of the School of Oriental and African Studies 65, no. 1 (2002): 1-30.

The Conference of Jewish Relations (1953), 83. L'ensemble de la contribution, 68-83. La partie qui nous occupe est 2) Qur'ān 122.2: Aṣ-ṣamad, p. 72-83.

112 Smith, The Ugaritic Baal Cycle, 1: 340-341.

113 Sfar, Le Coran est-il authenthique?, 101. 
Bowersock, Glen W. The Throne of Adulis: Red Sea Wars on the Eve of Islam. Oxford: Oxford University Press, 2013.

Burton, John. The Collection of the Qur'ān. Cambridge: Cambridge University Press, 1977.

Casanova, Paul. Mohammed et la fin du monde. Étude critique sur l'islam primitif. Paris: Paul Geuthner, 1911-1924.

Chabbi, Jacqueline. Les trois piliers de l'islam : lecture anthropologique du Coran. Paris: Seuil, 2016.

Chabbi, Jacqueline. Le Seigneur des tribus: l' islam de Mahomet. Paris: Noêsis, 1997.

Denny, Frederick Mathewson. «Some Religio-Communal Terms and Concepts in the Qur'ān.» Numen 24 (1977): 20-59.

Donner, Fred. Muhammad and the Believers. At the Origins of Islam. Cambridge: The Belknap Press, 2010.

Donner, Fred. «From Believers to Muslims. Confessional Self-Identity in the Early Islamic Community. » Al-Abhath 50-51 (2002-2003): 9-53.

$E Q=$ Encyclopaedia of the Qur'ān, 6 vols., edited by Jane Dammen McAuliffe, et al. Leiden: Brill, 2001-20o6.

Ess, Josef van. [TG] = Theologie und Gesellschaft im 2. und 3. Jahrhundert Hidschra. Eine Geschichte des religiösen Denkens im frühen Islam. 6 vols. Berlin: Walter de Gruyter, 1991-1997.

Faris, Nabih Amin, and Harold Walter Glidden. «The Development of the Meaning of Koranic Hanïf.» Journal of the Palestine Oriental Society 19 (1939-1940): 1-13.

Al-Fīrūzābādī, Abū al-Ṭāhir Muhyī al-Dīn M. b. Ya'qūb al-Shīrāzì. al-Qāmūs al-muhịṭ, Beirut: Mu'assasat al-Risāla, 1407/1987.

Flügel, Gustav. Mani, seine Lehre und seine Schriften. Aus dem Fihrist des Abû'lfaradsch Muhammad ben Ishak al-Warrâk, bekannt unter dem Namen Ibn AbîJa'kûb an-Nadîm [...], im Text nebst Uebersetzung, Commentar und Index. Leipzig: Brockhaus, 1862.

Gil, Moshe. «The Creed of Abū 'Āmir.» Israel Oriental Studies 12 (1992): 9-57.

Gilliot, Claude. «Collecte ou mémorisation du Coran. Essai d' analyse d'un vocabulaire ambigu.» In Hadītstudien:Die Überlieferungen des Propheten im Gespräch. Festschrift für Prof. Dr. Tilman Nagel, edited by Rüdiger Lohlker, 77-132. Hamburg: Verlag Dr. Kovač, 2009.

Gilliot, Claude. «Muhammad, le Coran et les contraintes de l'histoire.» In The Qur'ān as text, edited by Stefan Wild, 3-26. Leiden: Brill, 1996.

Gilliot, Claude. «Narratives.» EQ 3, 516-528.

Gilliot, Claude. «Poète ou prophète? Les traditions concernant la poésie et les poètes attribuées au prophète de l'islam et aux premières générations musulmanes.» In Paroles, signes, mythes. Mélanges offerts à Jamal Eddine Bencheikh, edited by Floréal Sanagustin, 331-396. Damas: IfEAD, 2001.

Gilliot, Claude. «Rétrospectives et perspectives. De quelques sources possibles du 
Coran mecquois. (I). Les sources du Coran et les emprunts aux traditions religieuses antérieures dans la recherche (xıxe et début du xxe siècles).» In Perspectives on Islamic Culture. Essays in Honour of Emilio G. Platti, edited by Bert Broeckaert, Stef Van den Branden and Jean Jacques Pérennès, 19-51. Louvain-Paris, Peeters (Les Cahiers du MIDEO, 6), 2013.

Gilliot, Claude. «Les traditions sur la composition ou coordination du Coran (ta'lif alqur'ān).» In Das Prophetenhadīt. Dimensionen einer islamischen Literaturgattung, edited by Claude Gilliot and Tilman Nagel, 14-39. Göttingen: Vandenhoeck \& Ruprecht, 2005 .

Gilliot, Claude. «Die Schreib- und/oder Lesekundigkeit in Mekka und Yathrib/Medina zur Zeit Mohammeds.» In Schlaglichter: Die beiden ersten islamischen Jahrhunderte, edited by Markus Groß and Karl-Heinz Ohlig, 293-319. Berlin: Verlag Hans Schiler, 2005 .

Gilliot, Claude. «Un verset manquant du Coran ou réputé tel.» In En hommage au Père Jacques Jomier, o.p., edited by Marie-Thérèse Urvoy, 73-10o. Paris: Cerf, 2002.

Gilliot, Claude, et Pierre Larcher, «Language and Style of the Qur’ān. » EQ 3, 109-135.

Grünbaum, Max. «Miscellen. » Zeitschrift der Deutschen Morgenländischen Gesellschaft $42(1888): 45-55$.

Grunebaum, Gustav Edmund von. Classical Islam: A History, 600 A.D. to 1258A.D., translated by Katherine Watson. London: Allen and Unwin, 1970.

Guillaume, Alfred. The Life of Muhammad: A Translation of Ibn Ishaq's Sirat RasulAllah. Karachi: Oxford University Press, 1955.

al-Ḥākim al-Nīsābūrī. al-Mustadrak 'alā al-Ṣaḥịhayn fí al-ḥadīth. Edited by M. 'Arab b. Muhammad Ḥusayn et al. 4 vols. Hyderabad, 1334-1342/1915-1923.

Hawting, Gerald R. The Idea of Idolatry and the Emergence of Islam: From Polemic To History. Cambridge: Cambridge University Press, 1999.

Hirschfeld, Hartwig, New Researches into the Composition and Exegesis of the Qoran. London: Royal Asiatic Society, 1902.

Horovitz, Josef. Koranische Untersuchungen. Berlin and Leipzig: Walter de Gruyter, 1929.

Ibn 'Arafa, Abu 'Abdallah Muḥammad al-Warghamī al-Tūnisī al-Mālikī. Tafsīr Ibn 'Arafa. Edited by Jalāl al-Asyūṭi 4 vols. Beirut: DKI, 2008.

Ibn Ḥajar al-'Asqalānī. Fath al-bārī bi-šarh Șaḥịh al-Bukhārī. Edited by Muhibb al-Dīn al-Khațīb. 13 vols. Cairo : al-Mațba'a al-salafiyya, 1379-139o/196o-197o.

Ibn Ḥanbal, Musnad. Edited by Muḥammad al-Zuhrī al-Ghamrāwī. 6 vols. Cairo: alMațba'a al-Maymaniyya, 1313/1895.

Ibn Ḥanbal, Musnad. Edited by Aḥmad Muḥammad Shākir, al-Ḥusaynī 'Abd al-Majīd Hāshim and 'Umar Hāshim. 20 vols. Cairo: Dār al-Ḥadīth, 1416/1995.

Ibn Manẓūr, Jamāl al-Dīn Abū l-Faḍl M. b. al-Mukarram b. 'A. al-Khazrağī al-Anșāīī alIfrīqī al-Miṣrī. Lisān al-'Arab. 15 vols. Beirut: Dār Șādir, 1955 (text established on the basis of the Būlāq edition, 2o vols., 1300-1308/1882-189o). 
Ibn al-Nadīm, Abū l-Faraj M. b. a. Ya'qūb. The Fihrist of al-Nadìm. A Tenth-Century Survey of Muslim Culture. Edited and translated by Bayard Dodge. 2 vols. New York: Columbia University Press, 1970.

Ibn Sīda. Abū l-Ḥasan 'Alī b Ismā'īl al-Andalusī. al-Muhkam wa l-muḥ̂ṭ al-ázam. Edited by Abd al-Hamīd. Beirut: Dār al-Kutub al-ilmiyya, 1421/200o.

al-Jawharī, Abū Naṣr Ismāc̄il b. Ḥammād al-Turkī al-Fārābī. al-Ṣihạḥ [Tāj al-lugha wa șị̂ạh al-'arabiyya]. Edited by A. 'Abd al-Ghafūr 'Ațțār. 6 vols. Cairo: Mațābi' Dār alK. al-K. al-'arabī, 1376-1377/1956-57; reprint Beirut: Dār al-'Ilm li-l-malāyīn, 1979.

Jeffery, Arthur. The Foreign Vocabulary of the Qur'ān. Baroda: Oriental Institute, 1938. Jeffery, Arthur. Materials for the History of the Text of the Qur'ān. Leiden: Brill, 1937.

Joüon, Paul. «Yđoxpı †ท dans l'Évangile et hébreu hanef.» Recherches de Sciences Religieuses 20 (1930): 312-316.

Juynboll, Gautier H.A. «Shu'ba b. al-Ḥadjdjādj. . In Encyclopaedia of Islam, 2nd edition, vol. IX, edited by P. Bearman, Th. Bianquis, C.E. Bosworth, E. van Donzel, and W.P. Heinrichs. Leiden: 1997, 510-511.

Juynboll, Gautier H.A. «Shu'ba b. al-Hajjāj (d. 16o/776) and His Position among the Traditionists of Bașra.» Le Muséon 111 (1998): 187-226.

Juynboll, Gautier H.A. «al-Sha'bī.» In Encyclopaedia of Islam, and edition, vol. IX, vol. IX, edited by P. Bearman, Th. Bianquis, C.E. Bosworth, E. van Donzel, and W.P. Heinrichs. Leiden: Brill, 1997, 162-163.

Juynboll, Gautier H.A. Encyclopedia of Canonical Hadith. Leiden: Brill, 2007.

Juynboll, Gautier H.A. «The Role of the Mu'ammarūn in the Early Development of the isnād.» Wiener Zeitschrift für die Kunde des Morgenlandes 81 (1971): 155-175, repr. in Juynboll, Studies on the Origins and Uses of Islamic hadith (Aldershot: Variorum, 1996), VII.

Juynboll, Gautier H.A. Studies on the Origins and Uses of Islamic hadīth. Aldershot: Variorum, 1996.

Juynboll, Gautier H.A. Muslim Tradition: Studies on Chronology, Provenance and Authorship of Early Hadith. Cambridge: Cambridge University Press, 1983.

al-Khamash, Salim S. "Aḍdād: a Study of Homo-Polysemous Opposites in Arabic." PhD diss. Bloomington, IN : Indiana University, 1991.

Lane, Edward William. [Madd al-Qāmūs] An Arabic-English Lexicon. 2 vols. Cambridge: Islamic Texts Society Trust, 1984 (The original edition, 8 vols., London 1863-1874 and Supplements for 7 and 8, 1877-1893).

Laurent, Annie, dirigé par. Vivre avec l'islam. Réflexions chrétiennes sur la religion de Mahomet. Versailles: Éditions Saint-Paul, 1996.

Levy-Rubin, Milka. «Praise or defamation? On the Polemical Usage of the Term hanif among Christians and Muslims in the Middle Ages.» Jerusalem Studies in Arabic and Islam 28 (2003): 202-224.

Maçoudi [= al-Mas'ūdī] . Le Livre de l'Avertissement et de la revision. Translated by B. Carra de Vaux. Paris: Imprimerie nationale, 1896. 
Marouzeau, Jules. Lexique de la terminologie linguistique. Paris: P. Geuthner, 1933.

al-Mas'ūìi. Bibliotheca Geographorum Arabicorum. Vol. 8 Kitāb al-tanbīh wa-l-ishrāf.

Edited by Michael J. de Goeje. Leiden: Brill, 1894.

Michaelis, Johann David. Supplementa ad Lexica Hebraica. 6 vols. Göttingen: Johann Georg Rosenbusch, 1792.

al-Mizzī. Tahdhīb al-kamāl fí asmā' al-rijāl. Edited by Bashshār 'Awwād Ma'rūf. 35 vols.

Beirut: Mu'assasat al-Risāla, 1400-1404/1980-1985.

Moubarac, Youakim. Abraham dans le Coran. L'histoire d'Abraham dans le Coran et la naissance de l'Islam. Paris: J. Vrin, 1958.

Nöldeke, Theodor. Geschichte des Qorāns, 2. Auflage, edited by Friedrich Schwally, 3 vols. Leipzig: Dietrich, 19o9-1938.

Nöldeke, Theodor. The History of the Qur'ān. Edited and translated by Wolfgang H. Behn. Leiden: Brill, 2012. Arabic trans. of this work by Georges Tamer. Ta'rīkh al-Qur'ān. Beirut: Konrad-Adenauer Stiftung, 2005.

Paret, Rudi (trans.). Der Koran. Darmstadt: Wissenschaftliche Buchgesellschaft, 1975.

Prémare, Alfred-Louis de. «L'islam comme monoprophétisme. » In Vivre avec l'islam.

Réflexions chrétiennes sur la religion de Mahomet, edited by Annie Laurent 150-162. Versailles: Éditions Saint-Paul, 1996.

Puin, Gerd-Rüdiger. «Observations on Early Qur’ān Manuscripts in Șan’ā’.» In The Qur'ān as Text, edited by Stefan Wild, 109-135. Leiden: Brill, 1996.

al-Qurțubī. al-Jāmic li-ậkām al-Qur'ān, 2nd edition. Edited by Aḥmad 'Abd al-'Alīm alBardūnī et Ibrāhīm Aṭfayyish. 20 vols. Cairo : al-Hay’a al-mișriyya al-āmma li-l-kitāb, 1372-1387/1952-1967.

Reeth, Jan M.F. van. «Les prophéties oraculaires dans le Coran et leurs antécédents:

Montan et Mani.»In Controverses sur les écritures canoniques de l'islam, edited by Daniel de Smet and Mohammad Ali Amir-Moezzi 109-113. Paris: Cerf, 2014.

Reynolds, Gabriel Said. The Qur'ān and its Biblical Subtext. London: Routledge, 2010. Rippin, Andrew. «RHMNN and the Hanīfs.»In Islamic Studies Presented to Charles J. Adams, edited by Wael B. Hallaq and Donald P. Little 153-168. Leiden: Brill, 1991.

Rippin, Andrew. «Ubayy b. Ka'b.» In Encyclopaedia of Islam, 2nd edition, vol. x, edited by P. Bearman, Th. Bianquis, C.E. Bosworth, E. van Donzel, and W.P. Heinrichs. Leiden: Brill, 200o, 764-765.

Rosenthal, Franz. «Some Minor Problems in the Qur’an.» In The Joshua Starr Memorial Volume. Studies in History and Philology. New York: The Conference of Jewish Relations (Jewish Social Studies Publications, 5), 1953.

Rubin, Uri. «Hanīfiyya and Ka'ba: An Inquiry into the Arabian Pre-Islamic Background of dīn Ibrāhīm.» Jerusalem Studies in Arabic and Islam 13 (1990): 85-103.

Rückert, Friedrich. Der Koran, in der Übersetzung von Friedrich Rückert, third edition.

Edited by Hartmut Bobzin. Würzburg: Ergon, 2000.

Saleh, Walid. «The etymological fallacy and Qur’anic studies: Muhammad, paradise, 
and late antiquity.» In The Qur'àn in Context: Historical and Literary Investigations into the Qur'ānic Milieu, edited by Angelika Neuwirth 649-698. Leiden: Brill, 2010.

Sfar, Mondher. L'autre Coran. Paris: Editions Sophonisbe, 2016.

Sfar, Mondher. Le Coran est-il authenthique? Paris: Les Éditions Sfar (diffusion Cerf), 2000.

Sirry, Mun'im. «The Early Development of the Quranic ḥanīf.» Journal of Semitic Studies 59, no. 2 (2011): 349-355.

Smith, Mark Stratton. The Ugaritic Baal Cycle, 1 , Introduction with Text, Translation and Commentary of KTU I.I-I-2. Leiden: Brill 1994.

Snouck Hurgronje, Christiaan. Het Mekkaansche Feest. Leiden: Brill, 188o.

Snouck Hurgronje, Christiaan. «Une nouvelle biographie de Mohammed.» Revue de l'histoire des religions 30 (1894): 48-70, 149-178 [= recension de Hubert Grimme, Mohammed, vol. 1, 1892].

Sprenger, Aloys. Das Leben und die Lehre des Mohammeds. 3 vols. Berlin: Nicolaische Verlagsbuchhandlung, 1869 .

Stroumsa, Guy G. «Jewish Christianity and Islamic Origins.» In Islamic culture, Islamic Contexts: Essays in Honour of Professor Patricia Crone, edited by Asad Q. Ahmed, Behnam Sadeghi, Robert G. Hoyland and Adam Silverstein 72-96. Leiden: Brill, 2015 .

al-Suyūṭ̂̀, al-Itqān fí 'ulūm al-Qur'ān. Edited by Muḥammad Abū al-Faḍl Ibrāhīm. 4 vols. en 2. Cairo: al-Hay’a al-mișriyya al-āmma li-l-kitāb, 1974-1975.

al-Ṭabarī. Annales. Edited by Michael J. de Goeje, Jacob Barth, Theodor Nöldeke et al. 3 vols. (en 16 parties). Leiden: Brill, 1879-1901.

Tardieu, Michel. «Histoire des syncrétismes de la fin de l'Antiquité: Le concept de religion abrahamique.» Annuaire du Collège de France 106 (2005-2006) : 435-440.

al-Ṭayālisī. al-Musnad. Hyderabad: Dā'irat al-ma‘̄āif al-nizāāmiyya, 1321/1903.

Torrey, Charles Cutler. The Jewish Foundation of Islam. New York: Jewish Institute of Religion Press, 1933.

al-Tirmidhī. al-Jāmi al-șaḥịh. Edited by Aḥmad Muḥammad Shākir, Muḥammad Fu'ād 'Abd al-Bāqī and Ibrāhīm 'Ațwah 'Awaḍ. 5 vols. Cairo: Muṣțafā al-Ḥalabī, 1357-1381/ 1938-1962.

Vollers, Karl. «Das Religionsgespräch von Jerusalem (um 8oo D.), aus dem Arabischen übersetzt. » Zeitschrift für Kirchengeschichte 29 (1908): 29-71, 197-221.

Wansbrough, John. Quranic Studies. Sources and Methods of Scriptural Interpretation. Oxford, London: Oxford University Press, 1977.

Watt, William Montgomery. Mahomet à La Mecque. Translated by François Dourveil. Paris: Payot, 1977.

Watt, William Montgomery. «Hanīf.» In Encyclopaedia of Islam, 2nd edition, vol. III, edited by P. Bearman, Th. Bianquis, C.E. Bosworth, E. van Donzel, and W.P. Heinrichs 165-166. Leiden: Brill, 1971. 
Wellhausen, Julius. Skizzen und Vorarbeiten. Vol. 3 :Reste arabischen Heidentums. Berlin: Georg Reimer, 1887.

Wellhausen, Julius. Reste arabischen Heidentums. Berlin: Walter de Gruyter, 1927.

Wilde, Clare, and Jane Dammen McAuliffe. «Religious Pluralism in the Qurān.» EQ 4, 398-419.

al-Zajjāj. Ma'ānī al-Qur'ān wa i'rābuh. Edited by 'Abd al-Jalīl 'Abduh Shalabī. 5 vols. Beirut: 'Ālam al-kutub, 1408/1988.

Zellentin, Holger Michael. The Qur'ān's Legal Culture. The Didascalia Apostolorum as a Point of Departure. Tübingen: Mohr Siebeck, 2013.

al-Zabīdī, al-Sayyid Muḥammad Murtaḍā M. b. M. al-Ḥusaynī. Tāj al-'arūs min jawāhir al-Qāmūs. Edited by 'Abd al-Sattār Aḥmad Farāj et al. 40 vols. Kuwayt: Wizārat alI'lām, 1385-1422/1965-2001. 